\title{
Commentary
}

\section{Policy for the complex burden of malnutrition in Africa: a research agenda to bring consumers and supply chains together}

\author{
First published online 22 December 2016
}

\begin{abstract}
It is Tuesday afternoon and Refilwe leaves her job as a cleaner to begin her two-hour journey to her home in the Pretoria urban area of Mamelodi. After the minibus taxi drops her off a few streets from her bome, she stops to buy vegetables from the street vendors at the taxi rank, before visiting a spaza storea small-scale informal convenience store ${ }^{(1)}-$ to buy tea, sugar and more food for her family's dinner; she is already planning a trip to the large supermarket on the outskirts of her residential area on the weekend.

What is available for her to purchase at each of these venues? Imported rice, local white bread or traditional maize? Packaged biscuits, processed snack foods, or fruit and vegetables? What factors underlie ber decisions to buy certain foods from different venues? What factors constrain or enable her to consistently source bealthy food for her family?
\end{abstract}

These questions get to the heart of how consumers interact with the changing food supply patterns in urban Africa. As the emerging burden of diet-related noncommunicable diseases establishes itself firmly alongside food insecurity and undernutrition in urban centres, nutrition policy research needs to consider in more detail the interaction between consumers and their food supply. Where are different foods purchased, and why? What influences consumer purchasing patterns, and how could policy be used to incentivize a food supply that delivers healthier food, where and when consumers need it?

In this commentary, we consider the benefits of food supply-focused research in identifying effective policy interventions to address the dual burden of malnutrition in Africa. We then highlight an under-researched dimension of the food supply chain, which is at the point of interaction with consumers, and provide a short case study from South Africa to illustrate the potential benefits of strengthening this research focus.

\section{The dual burden of malnutrition in Africa and the changing food supply}

The emerging dual burden of malnutrition in Africa is at a nascent stage; but persistent, high rates of undernutrition are increasingly accompanied by rising rates of overweight and risk factors for non-communicable diseases, particularly in urban areas ${ }^{(2,3)}$. For example, in Burkina Faso, rates of overweight and obesity in an urban population were found to be $24 \%$, with similarly high rates of hypertension, hyperglycaemia and low HDL cholesterol. In addition, in $24 \%$ of participants, one of these cardiometabolic risk factors was coexisting with either iron depletion or vitamin A deficiency, with a higher prevalence of this 'double burden' observed in the lowincome group ${ }^{(4)}$. Similarly, a study in urban Kenya found a prevalence of childhood stunting of $46 \%$ and underweight of $11 \%$, while $9 \%$ of children were overweight/obese; $8 \%$ of their mothers were underweight and $32 \%$ were overweight/obese ${ }^{(5)}$. The nutrition transition in urban South Africa is at an even later stage ${ }^{(6)}$. While the prevalence of stunting among children in South Africa has declined over the past 40 years, it remains at about $25 \%{ }^{(7)}$. At the same time, the recent South African National Health and Nutrition Examination Survey found a prevalence of obesity of $39 \%$ among women and $11 \%$ among men ${ }^{(8)}$, and high prevalences of impaired glucose levels (nearly $20 \%)$ and diabetes (10\%).

As the urban population has increased in Africa, so has the challenge of delivering a safe, healthy, acceptable and affordable urban food supply ${ }^{(9)}$. Healthier food choices are now often more expensive than commonly consumed, less healthy foods ${ }^{(10)}$. Urbanization is changing job markets throughout the informal, semi-formal and formal economy, as well as impacting rural livelihoods ('rubanization') and food procurement patterns ${ }^{(11)}$. Agricultural production is shifting away from subsistence agriculture, as rural households seek to diversify their livelihoods, yet large-scale agriculture still faces challenges in effectively supplying urban populations ${ }^{(9,12)}$. Throughout sub-Saharan Africa, countries are experiencing increasing import dependence for staple food supplies, at the same time as a complex network of informal traders continues to operate across regional borders ${ }^{(9)}$. Global and regional trade and investment are also increasing the availability and affordability of highly processed foods and sweetened beverages ${ }^{(13)}$.

Urban populations demonstrate complex approaches to food procurement, including purchase from the formal and informal sectors, food transfers and own production $^{(14)}$. In particular, the informal sector (e.g. hawkers, 
small stores, informal roadside stalls) plays an essential role in making food accessible to the urban poor ${ }^{(14,15)}$. However, there is also considerable evidence for the impact of formal food retailers on the food supply chain, particularly in terms of integrating supply chains and increasing buyer power, and a growing dependence of urban populations in Africa on purchased food ${ }^{(16-18)}$. Supermarket retail in Africa has grown substantially during the past two decades. For example, supermarkets in Kenya represented a tiny niche in the early 2000s but by 2005 had grown to represent a fifth of food retail, with half of their customers from low-income and poor consumers $^{(19)}$. However, there are often significant differentials in access to supermarkets between lowincome and high-income populations, which contribute to food insecurity among the urban poor ${ }^{(15,20,21)}$.

\section{Policy to improve the food supply}

There is an urgent need for early, sustained policy intervention in Africa to avert the diet-related non-communicable disease epidemic experienced in other regions and to achieve the Sustainable Development Goals related to nutrition ${ }^{(22)}$. Improving the food supply to support enhanced dietary quality and diversity will be an integral component of such intervention ${ }^{(23)}$. A food supply-based approach entails considering inputs into production, agricultural production, food processing and food retail to identify levers to help to improve the availability, accessibility, acceptability and affordability of healthier relative to less healthy foods ${ }^{(24)}$.

A food supply-based approach is essential for low- and middle-income countries, in which consumers are strongly influenced by affordability and availability, due to price sensitivity and often limited transport options. However, global recommendations for improving the food supply such as fiscal policy intervention or labelling ${ }^{(25)}-$ tend to be most effective in the formal food sector, and the significant role of the informal food sector for urban consumers has created challenges for adapting these to lower-income contexts ${ }^{(26)}$. In Lusaka, Zambia, among the poorest population quintile, only $1.2 \%$ of staple purchases were made in supermarkets ${ }^{(27)}$. In addition, general agriculture-focused intervention has a weak direct track record in flowing through to improvements in nutrition outcomes, likely due to the complex and gendered interaction between consumers and modern supply chains ${ }^{(28,29)}$.

This points to the need for food supply-focused research to support such policy intervention to address the dual burden of malnutrition in Africa, by identifying specific opportunities to improve access to (and consumption of) healthier foods. There is significant potential to improve affordability and availability of healthy foods in the African context, through in-depth analysis of the supply chain ${ }^{(30)}$. For example, researchers at the International Food Policy Research Institute have identified a wide range of strategies to identify food supply policy levers for reducing undernutrition in low- and middle-income countries, focusing on agriculture-sensitive intervention, intersectoral policy coherence and food-based approaches $^{(31-35)}$. Similarly, food supply-focused research has been used to identify effective and feasible policy interventions to reduce trans-fats in both the formal and informal food system in India ${ }^{(36)}$ and to identify a range of agricultural, commerce and trade policy interventions to improve the food supply in Pacific Island countries ${ }^{(37,38)}$. In South Africa, recent research regarding a sugarsweetened beverage tax has highlighted the importance of - and likely effectiveness of - taking a food supply policy approach to improving nutrition ${ }^{(39,40)}$.

\section{But what about consumers?}

The food supply-focused research described above generally focuses on the 'production and distribution' components of the food supply chain, and has revealed opportunities for a wide range of contextually relevant interventions with the potential to increase the affordability and availability of healthier foods relative to less healthy foods.

However, one of the key determinants of food security in urban Africa is food access; there is a complex interplay between the formal and informal sectors, as well as agricultural own production, in how urban populations access food $^{(15)}$. How consumers interact with their multiple food environments, particularly in a poor urban context, is still relatively unknown. A more 'people-centred' approach to food supply research that considers people as "choice makers' rather than simply 'consumers' can help to unpack the two-way flow of information between the food supply and consumers; in particular, in understanding consumer decision making regarding where and why they choose to purchase different types of healthier and less healthy foods, including issues of convenience, acceptability, availability and affordability. Research that looks from a consumer perspective, 'down' the food supply chain, can thus complement our growing understanding of policy levers to improve affordability, accessibility and availability of healthier foods (Fig. 1).

The primary benefit of improved understanding of consumer engagement with food value chains by nutrition policy makers is the potential to enhance consumer access to healthier supply chains. For example, a combination of supply- and demand-based interventions might successfully increase affordability and availability of fruits and vegetables, as well as consumer demand and capacity for consumption (e.g. food skills). However, if the increased supply is mediated by supermarkets, and research into consumer interaction with supply chains indicates that these are accessed only by certain subpopulations, the impact of the intervention will be limited. Contextual understanding of consumer engagement with 


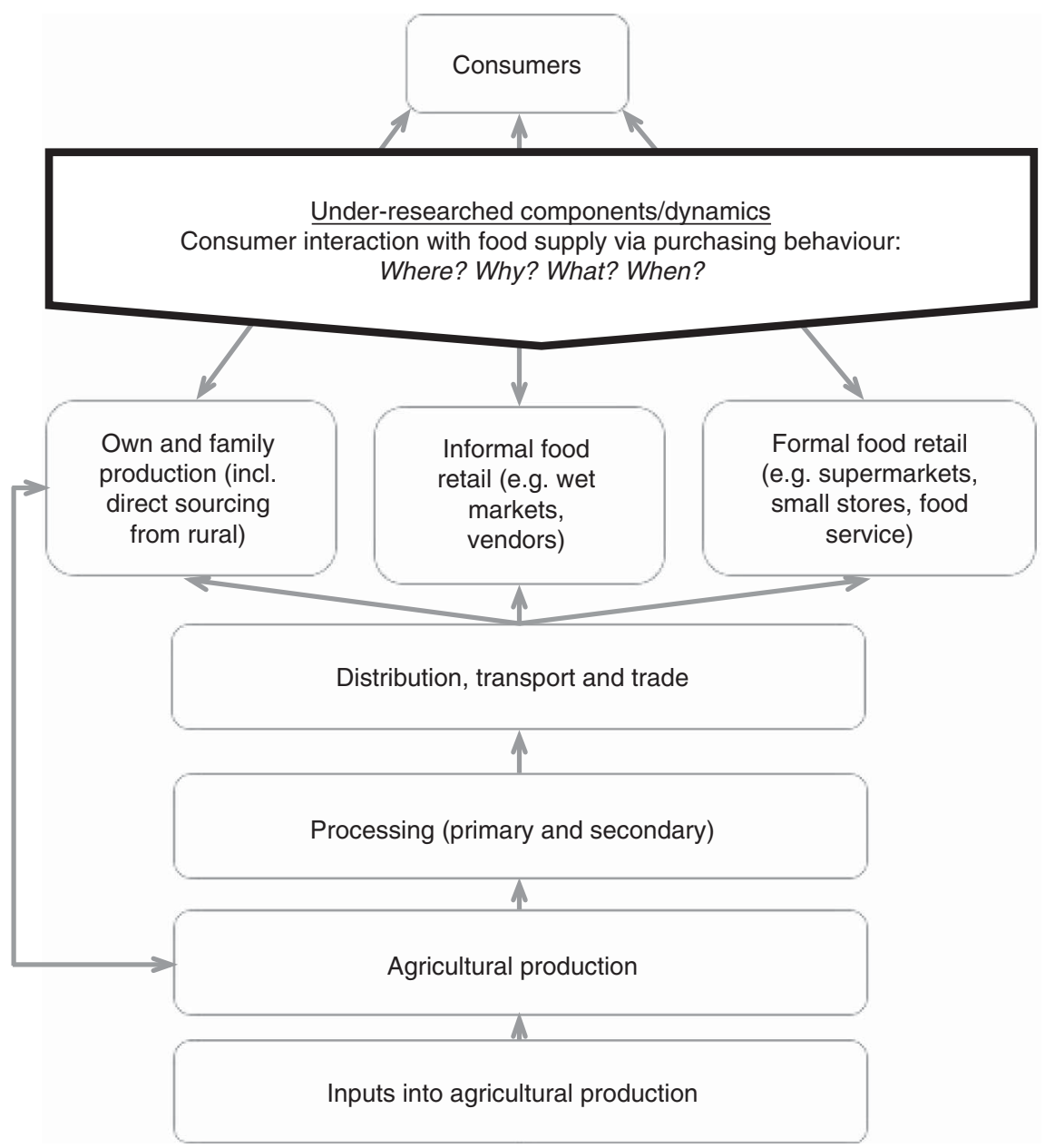

Fig. 1 An opportunity to integrate a 'consumer' focus into food supply research for nutrition

the food supply might lead to the strategic design of interventions such that the improvements to supply benefit a wider variety of retail outlets, including the informal sector.

\section{How a consumer focus can add nutrition policy value: a case study of South Africa}

South Africa continues to face the interrelated challenges of food insecurity, undernutrition and diet-related noncommunicable diseases, and the need for a strong policy response is widely acknowledged ${ }^{(41,42)}$. To return to our introductory case study, Refilwe's decision making is occurring within a changing food supply and her decisions are shaped by complex historical, social, economic and personal factors ${ }^{(43)}$. However, her decisions are also shaped by her limited access to healthy affordable food: she is likely to encounter a food environment that struggles to maintain a reliable supply of fresh fruit and vegetables for a growing urban population, expensive staple foods at local spaza stores with minimal economies of scale, pricing incentives that favour cheap highly processed foods and sweet beverages, and a requirement for convenience as the result of her own limited transport options, time and poor access to affordable cooking fuel ${ }^{(10,13,44-46)}$.

Considering Refilwe's access to fresh fruits as one important component of a healthy diet can help to exemplify how consideration of how, where, when and why consumers access food can be used to identify specific policy opportunities. Access to fruit in certain urban areas of South Africa is primarily through the informal market; in particular, wet markets or stalls and street vendors ${ }^{(14)}$. Specific policy opportunities in South Africa that could increase access are: targeted support for peri-urban farmers to access urban markets (e.g. transport) ${ }^{(47)}$; including food production considerations in initiatives for urban greening $^{(48)}$; and, given the finding that fruit is one of the most commonly consumed street foods ${ }^{(49)}$, initiatives that could increase access to, or incentivize the sale of, fresh fruit and vegetables by street vendors.

Expanding food supply research to address the double burden of malnutrition will require a multidisciplinary ethos covering a range of diverse fields of study from policy analysis to public health nutrition research, value chain analysis and consumer behaviour studies. 


\section{Acknowledgements}

Financial support: This work was partially supported by the Australia Africa Universities Network (AAUN) grant held by J.N. for 2015, titled 'Where does your food come from? Food supply in the context of trade, agriculture and nutrition'. The AAUN had no role in the design, analysis or writing of this article. Conflict of interest: None. Authorship: All authors contributed to the research questions identified in the commentary. A.M.T. drafted the manuscript and all authors contributed to the writing. Ethics of human subject participation: No ethical approval was required for the work presented herein.

Anne Marie Thow ${ }^{1}$, Annemarie Viljoen ${ }^{2}$, Hettie Schönfeldt ${ }^{3}$, Riette deKock $^{4}$, Gerrie duRand ${ }^{2}$, Gerda Gericke ${ }^{5}$ and Joel Negin ${ }^{6}$

${ }^{1}$ Menzies Centre for Health Policy Level 6 The Hub

Charles Perkins Centre D17 The University of Sydney NSW 2006, Australia Email annemarie.thow@sydney.edu.au

${ }^{2}$ Department of Consumer Science University of Pretoria Pretoria, South Africa

${ }^{3}$ Faculty of Natural and Agricultural Sciences University of Pretoria Pretoria, South Africa

${ }^{4}$ Department of Food Science University of Pretoria Pretoria, South Africa

${ }^{5}$ Department of Human Nutrition University of Pretoria Pretoria, South Africa

${ }^{6}$ School of Public Health University of Sydney Sydney, NSW, Australia

\section{References}

1. Sustainable Livelihoods Foundation (2016) South Africa's Informal Economy: Research Findings from Nine Townships. Capetown: Sustainable LIvelihoods Foundation.

2. Tzioumis E \& Adair LS (2014) Childhood dual burden of under- and overnutrition in low- and middleincome countries: a critical review. Food Nutr Bull 35, 230-243.

3. Popkin BM, Adair LS \& Ng SW (2012) Global nutrition transition and the pandemic of obesity in developing countries. Nutr Rev 70, 3-21.
4. Zeba AN, Delisle HF, Renier G et al. (2012) The double burden of malnutrition and cardiometabolic risk widens the gender and socio-economic health gap: a study among adults in Burkina Faso (West Africa). Public Health Nutr 15, 2210-2219.

5. Kimani-Murage EW, Muthuri SK, Oti SO et al. (2015) Evidence of a double burden of malnutrition in urban poor settings in Nairobi, Kenya. PLOS ONE 10, e0129943.

6. Nnyepi MS, Gwisai N, Lekgoa M et al. (2015) Evidence of nutrition transition in Southern Africa. Proc Nutr Soc 74, 478-486.

7. Said-Mohamed R, Micklesfield LK, Pettifor JM et al. (2015) Has the prevalence of stunting in South African children changed in 40 years? A systematic review. BMC Public Health 15, 534 .

8. Shisana O, Labadarios D, Rehle $\mathrm{T}$ et al. (2014) South African National Health and Nutrition Examination Survey (SANHANES-1). Cape Town: HSRC Press.

9. Dubbeling M (2010) The Growth of Cities in East Africa: Consequences for Urban Food Supply. Leusden: RUAF Foundation.

10. Temple NJ \& Steyn NP (2011) The cost of a healthy diet: a South African perspective. Nutrition 27, 505-508.

11. Nielson A (2016) South Africa's Not so Traditional, Traditional Trade. New York: The Nielson Company.

12. Baiphethi MN \& Jacobs PT (2009) The contribution of subsistence farming to food security in South Africa. Agrekon 48, 459-482.

13. Thow AM, Sanders D, Drury E et al. (2015) Regional trade and the nutrition transition: opportunities to strengthen NCD prevention policy in the Southern African Development Community. Glob Health Action 8, 28338.

14. Crush J \& Frayne B (2010) Pathways to Insecurity: Food Supply and Food Access in Southern African Cities. Capetown: African Food Security Urban Network.

15. Crush J \& Frayne B (2011) Supermarket expansion and the informal food economy in Southern African cities: implications for urban food security. J South Afr Stud 37, 781-807.

16. England A (2015) Africa's supermarket shopping revolution. Financial Times, 24 July. https:/www.ft.com/content/ 6c0f2576-30b3-11e5-8873-775ba7c2ea3d (accessed November 2015).

17. Battersby J \& Crush J (2014) Africa's urban food deserts. Urban Forum 25, 143-151.

18. Reardon T \& Hopkins R (2006) The supermarket revolution in developing countries: policies to address emerging tensions among supermarkets, suppliers and traditional retailers. Eur J Dev Res 18, 522-545.

19. Neven D, Reardon T, Chege J et al. (2006) Supermarkets and consumers in Africa. J Int Food Agribus Mark 18, 103-123.

20. Battersby J \& Peyton S (2014) The geography of supermarkets in Cape Town: supermarket expansion and food access. Urban Forum 25, 153-164.

21. Crush J \& Caesar M (2014) City without choice: urban food insecurity in Msunduzi, South Africa. Urban Forum 25, $165-175$.

22. United Nations (2015) Transforming Our World: The 2030 Agenda for Sustainable Development. New York: UN; available at https://sustainabledevelopment.un.org/post2015/ transformingourworld

23. Gelli A, Hawkes C, Donovan J et al. (2015) Value Chains and Nutrition: A Framework to Support the Identification, Design, and Evaluation of Interventions, IFPRI Discussion Paper no. 01413. Washington: DC: International Food Policy Research Institute.

24. Hawkes C (2009) Identifying innovative interventions to promote healthy eating using consumption-oriented food supply chain analysis. J Hunger Environ Nutr 4, 336-356.

25. World Health Organization (2013) Follow-up to the Political Declaration of the High-Level Meeting of the General Assembly on the Prevention and Control of 
Non-communicable Diseases. Sixty-Sixth World Health Assembly WHA66.10 Agenda Item 13.1, 13.2, 27 May 2013. Annex: Global Action Plan for the Prevention and Control of Noncommunicable Diseases 2013-2020. Geneva: WHO.

26. Downs SM, Thow AM, Ghosh-Jerath S et al. (2013) From Denmark to Delhi: the multisectoral challenge of regulating trans fats in India. Public Health Nutr 16 2273-2280.

27. Mason NM \& Jayne TS (2009) Staple Food Consumption Patterns in Urban Zambia: Results from the 2007/2008 Urban Consumption Survey. Food Security Collaborative Policy Briefs no. 36. Lusaka: Zambian Ministry of Agriculture and Cooperatives, Agricultural Consultative Forum and Michigan State University; available at http://purl.umn.edu/ 56810

28. Masset E, Haddad L, Cornelius A et al. (2011) A Systematic Review of Agricultural Interventions that Aim to Improve Nutritional Status of Children. London: EPPI-Centre, Social Science Research Unit, University of London.

29. Dangour AD, Hawkesworth S, Shankar B et al. (2013) Can nutrition be promoted through agriculture-led food price policies? A systematic review. BMJ Open 3, e002937.

30. Pinstrup-Andersen P (2013) Nutrition-sensitive food systems: from rhetoric to action. Lancet 382, 375-376.

31. Kadiyala S, Harris J, Headey D et al. (2014) Agriculture and nutrition in India: mapping evidence to pathways. Ann $N Y$ Acad Sci 1331, 43-56.

32. Gillespie S, van den Bold M, Hodge J et al. (2015) Leveraging agriculture for nutrition in South Asia and East Africa: examining the enabling environment through stakeholder perceptions. Food Sec 7, 463-477.

33. Ved R \& Menon P (2012) Analyzing Intersectoral Convergence to Improve Child Undernutrition in India: Development and Application of a Framework to Examine Policies in Agriculture, Health, and Nutrition, IFPRI Discussion Paper no. 01208. Washington: DC: International Food Policy Research Institute.

34. Ruel MT \& Alderman H (2013) Nutrition-sensitive interventions and programmes: how can they help to accelerate progress in improving maternal and child nutrition? Lancet 382, 536-551.

35. Arimond M, Hawkes C, Ruel MT et al. (2011) Agricultural interventions and nutrition: lessons from the past and new evidence. In Combating Micronutrient Deficiencies: Food-Based Approaches, pp. 41-75 [B Thompson and L Amoroso, editors]. Rome: FAO.

36. Downs SM, Thow AM, Ghosh-Jerath S et al. (2015) Identifying the barriers and opportunities for enhanced coherence between agriculture and public health policies: improving the fat supply in India. Ecol Food Nutr 54, 603-624.
37. Snowdon W, Lawrence M, Schultz J et al. (2010) Evidencebased policy solutions to promote a healthy food environment for the Pacific Islands. Public Health Nutr 13, 886-892.

38. Thow AM, Heywood P, Schultz J et al. (2011) Trade and the nutrition transition: strengthening policy for health in the Pacific. Ecol Food Nutr 50, 18-42.

39. Tugendhaft A, Manyema M, Veerman LJ et al. (2016) Cost of inaction on sugar-sweetened beverage consumption: implications for obesity in South Africa. Public Health Nutr 19, 2296-2304.

40. Myers A, Fig D, Tugendhaft A et al. (2015) Sugar and health in South Africa: potential challenges to leveraging policy change. Glob Public Health (Epublication ahead of print version).

41. Haggblade S, Duodu KG, Kabasa JD et al. (2016) Emerging early actions to bend the curve in sub-Saharan Africa's nutrition transition. Food Nutr Bull 37, 219-241.

42. Muzigaba M, Puoane T \& Sanders D (2016) The paradox of undernutrition and obesity in South Africa: a contextual overview of food quality, access and availability in the New Democracy. In Food Poverty and Insecurity: International Food Inequalities, pp. 31-41 [M Caraher and J Coveney, editors]. Cham: Springer International Publishing.

43. Battersby J \& McLachlan M (2013) Urban food insecurity: a neglected public health challenge. $S$ Afr Med J 103, 716-717.

44. Igumbor EU, Sanders D, Puoane TR et al. (2012) 'Big Food', the consumer food environment, health, and the policy response in South Africa. PLoS Med 9, e1001253.

45. Mashau ME, Moyane JN \& Jideani IA (2012) Assessment of post harvest losses of fruits at Tshakhuma fruit market in Limpopo Province, South Africa. Afr J Agric Res 7, 4145-4150.

46. Temple NJ, Steyn NP, Fourie J et al. (2011) Price and availability of healthy food: a study in rural South Africa. Nutrition 27, 55-58.

47. Mun Bbun T \& Thornton A (2013) A level playing field? Improving market availability and access for small scale producers in Johannesburg, South Africa. Appl Geogr 36, $40-48$.

48. Shackleton CM, Hebinck P, Kaoma H et al. (2014) Lowcost housing developments in South Africa miss the opportunities for household level urban greening. Land Use Policy 36, 500-509.

49. Steyn NP, Labadarios D \& Nel JH (2011) Factors which influence the consumption of street foods and fast foods in South Africa - a national survey. Nutr J 10, 104. 